\title{
Carta aberta a um jovem investigador clínico
}

Rosalvo Almeida*

Caro colega,

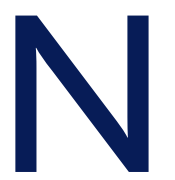

ão sei se já se apercebeu disso mas julgo que muitos médicos de família já se deram conta de que, nos tempos que correm, é cada vez mais frequente a realização de estudos de investigação clínica nas unidades de saúde da área dos cuidados primários.

Quase todos esses estudos são de tipo observacional, quantitativos, transversais. São questionários que se aplicam a utentes, familiares e cuidadores ou a profissionais de saúde. A grande maioria insere-se no contexto de graduações académicas - mestrados ou doutoramentos.

A realização destes estudos depende naturalmente da autorização dos dirigentes das unidades onde se concretizam, cabendo aos Conselhos Clínicos do ACES especiais competências na matéria. ${ }^{1}$ Em algumas ARS foram criadas Comissões de Ética para Saúde (CES) tendo em vista emitirem pareceres que ajudem os dirigentes nas suas decisões.

Há quem pense que os estudos observacionais ou, por outras palavras, aqueles em que não há intervenção sobre os participantes não carecem de parecer ético. Todavia, esta opinião assenta em alguns equívocos que importa resolver.

Em primeiro lugar, convém clarificar que os pareceres das CES não são vinculativos nem obrigatórios - os dirigentes são livres de deferir ou indeferir os pedidos de autorização qualquer que seja o sentido dos pareceres da CES e, por outro lado, podem decidir sem pedir parecer. Por sua vez, aos investigadores também interessa terem um parecer de uma CES pois algumas revistas, como esta, o exigem.

Em segundo lugar, o papel das CES é zelar pelos direitos e interesses dos participantes. Deste modo as comissões apreciam os projetos, verificam os conteúdos

*Presidente cessante da Comissão de Ética para a Saúde da ARS Norte (2009-2011), neurologista aposentado. dos inquéritos e as metodologias (nomeadamente quanto à forma como os participantes são convidados e recrutados), confirmam os compromissos de confidencialidade e anonimato, reconhecem a pertinência e relevância dos objetivos. Ora, estas finalidades da apreciação de projetos são independentes do tipo de estudo e são manifestamente importantes, sejam os estudos observacionais, experimentais ou outros. ${ }^{2}$

Também corre a opinião de que em estudos observacionais não há necessidade de obter, por assinatura de documento, o consentimento informado dos participantes. Aparentemente este outro equívoco resulta de um entendimento desfocado do que é o consentimento informado - é afinal olhar só para a palavra «consentimento»e menorizar a palavra «informado».

A utilização para fins de investigação de dados pessoais e de depoimentos dos participantes, sejam utentes ou profissionais de saúde, implica que os investigadores se comprometam a não os utilizar para outros fins, garantam não identificar os participantes na publicação dos resultados, expliquem em que consiste o estudo, não escondam os eventuais incómodos causados pelo estudo, etc. É por isso que um documento formal para dar informações e obter consentimento se torna necessário. Ele representa uma forma de «contrato» entre investigador e participante, feito em duplicado, em que cada parte fica com uma via assinada por ambos - o primeiro «outorgante» guarda-o para provar que pediu e obteve consentimento perante eventuais auditorias; o segundo «outorgante» guarda-o para reler, revogar se assim o entender ou reclamar se verificar eventual incumprimento do garantido. É óbvio que a linguagem deverá ser tão simples quanto possível, livre de termos técnicos (exceto quando os participantes forem profissionais de saúde) e globalmente adequada à literacia dos participantes a recrutar. $^{3}$

Existe um outro ponto que dá origem a mal-entendidos - trata-se do anonimato dos dados tratados nes- 
te tipo de estudos. Quando os investigadores contactam diretamente com os participantes, não podem ignorar a identidade destes, mas o que se lhes pede é que mantenham o anonimato (nunca revelem a sua identidade). Esta garantia não se deve confundir com a anonimização de dados de saúde que consiste na entrega, por parte das instituições, normalmente a partir de fontes informáticas, de dados expurgados de elementos de identificação. Outra situação diferente será a dos inquéritos de autopreenchimento voluntário e anónimo com devolução indireta (por exemplo, devolução por correio ou introdução em caixa fechada), pois neste caso não há lugar a assinatura de documento de consentimento.

Assim, note-se que a utilização de dados de saúde para fins de investigação, no respeito pela lei e pelos princípios da confidencialidade e privacidade, só é possível quando os respetivos titulares informada e expressamente o consintam ou quando os dados são fornecidos aos investigadores de modo anonimizado. $\mathrm{Na}$ impossibilidade de se conseguir qualquer das condições aqui referidas, um estudo pode ainda ser autorizado, se for efetuado por profissionais da própria instituição (com natural e habitual acesso aos dados), quando se revista de excecional interesse público e receba parecer favorável da Comissão de Ética local. ${ }^{4}$

Já quando os estudos são realizados por médicos do internato (colocados em fase de formação nas unidades de saúde onde decorram os estudos) e consistem em revisões casuísticas amplas, desde que garantam, nos respetivos protocolos de estudo, preservar o anonimato dos titulares e não pretendam criar uma base de dados com elementos de identificação pessoal dos utentes, cremos que poderão ser autorizados pelos Conselhos Clínicos, mediante o parecer dos respetivos Orientadores de Formação (a quem aliás cabe também a supervisão do estudo e da sua integridade ética).

Espero bem que estas linhas o possam ajudar caso esteja a pensar em realizar alguma investigação. Elas representam as opções que têm sido seguidas pela Comissão de Ética da ARS Norte nos três anos de funcionamento desde que foi criada. O número de processos cresce todos os anos (em 2010 e 2011 dobrámos e triplicámos os números de 2009). Penso que poderá encontrar informações úteis nas páginas da CES do portal http://www.arsnorte.min-saude.pt, embora não esteja aí patente a parte do nosso trabalho que consistiu em «negociar" com os investigadores alterações aos projetos que os tornaram mais interessantes. ${ }^{5}$ Tem sido intelectualmente muito gratificante ver esse trabalho reconhecido por muitos dos próprios investigadores. Desejo-lhe as maiores felicidades profissionais e pessoais.

\section{REFERÊNCIAS BIBLIOGRÁFICAS}

1. Art. $^{\circ} 26$. $^{\circ}$ do Decreto-lei n. ${ }^{\circ} 28 / 2008$, de 28 de fevereiro.

2. Claudot F, Alla F, Fresson J, Calvez T, Coudane H, Bonaïti-Pellié C. Ethics and observational studies in medical research: various rules in a common framework. Int J Epidemiol 2009 Aug; 38 (4): 1104-8.

3. Kho ME, Duffett M, Willison DJ, Cook DJ, Brouwers MC. Written informed consent and selection bias in observational studies using medical records: systematic review. BMJ 2009 Mar 12; 338: b866.

4. Art. $^{\circ} 4 .^{\circ}$ da Lei $.^{\circ} 12 / 2005$, de 26 de janeiro.

5. Shaw DM. The ethics committee as ghost author. J Med Ethics 2011 Dec; 37 (12): 706.

\section{ENDEREÇO PARA CORRESPONDÊNCIA}

rosalvo.almeida@gmail.com 